\title{
Serum manganese level in children with iron deficiency
}

\author{
Eman A. Mostafa', Rasha M. Hasanin', Hanan M. Hamed ${ }^{1}$, Ayat A. Motawei', \\ Gamal A. N. Yamamah', Gamila S.M. El-Saeed² \\ 'Department of Paediatrics, National Research Centre, Egypt \\ 2Department of Medical Biochemistry, National Research Centre, Egypt
}

\section{ABSTRACT}

Introduction: Iron deficiency (ID) is the most common nutritional deficiency all over the world, especially in developing countries, and it is an important public health issue in childhood. ID may be associated with excess trace element absorption such as manganese $(\mathrm{Mn})$ from the gastrointestinal tract. The present study investigated serum Mn concentrations in children with ID.

Material and methods: This interventional study included 63 children aged 5-12 years, with ID, using WHO criteria, compared with 30 age- and sex-matched controls. The children were recruited from paediatric clinics, Medical Research Excellence Centre (MREC) at the National Research Centre from August 2017 to December 2018. Serum Mn levels were measured by inductively coupled plasma mass spectrometer plus haematological and iron indices.

Results: Serum Mn concentration was significantly increased in children with ID compared with controls $(p<0.001)$, while there was significant reduction in haematological and iron indices in the ID group. The serum transferrin receptor and transferrin were higher in the ID group compared to controls, but not significantly. Multiple regression analysis showed negative correlation between serum $\mathrm{Mn}$ and serum iron, serum ferritin, and transferrin saturation percentage $(r=-0.33, p=0.01 ; r=-0.32, p=0.01 ; r=-0.3, p=0.02)$, respectively. Improvement in haematological and iron indices and Mn occurred after iron supplementation for eight weeks in the ID group.

Conclusions: High serum Mn concentration was reported in ID children of this age group that decreased significantly after oral iron therapy; hence, the Mn level must be assessed simultaneously with haematological and iron indices in case of ID state. Early diagnosis and treatment of ID in children is recommended both to avoid complications of ID and to decrease Mn toxicity risk, which may lead to neurodevelopmental and intellectual impairment.

KEY WORDS:

serum manganese, children, iron deficiency.

\section{INTRODUCTION}

Iron deficiency (ID) is the most popular nutritional deficiency all over the world, especially in developing countries, and it is the most important public health issue in childhood. There are no obvious data about how many people are affected by ID worldwide, but in the paediatric age group, according to the WHO (2001), 30\% of children aged $0-4$ years and $48 \%$ of children aged $5-14$ years have iron deficiency anaemia (IDA) [1]. In Egypt, IDA rates are as high as $64 \%$ in rural areas [2].

\section{ADDRESS FOR CORRESPONDENCE:}

Rasha M. Hasanin, Department of Paediatrics, National Research Centre, El Buhouth St., 12622 Cairo,

Egypt, ORCID: 0000-0002-1218-4383, e-mail: rashamahmoud97@yahoo.com 
In spite of the introduction of iron-fortified milk products and iron supplementation, the IDA prevalence is high in the first two years of life and is accompanied with a decline in psychomotor and mental development, which may be permanent [3]. The iron absorption is regulated by hepcidin, which is a small peptide secreted mainly from hepatocytes. It downregulates duodenal iron absorption [4].

Manganese $(\mathrm{Mn})$ is one of the trace elements found in iron and other minerals, and it plays an important role in growth and development of the brain, but high Mn may be toxic to the nervous system, leading to a decline in processing speed and working memory [5]. Several studies have shown increased $\mathrm{Mn}$ absorption in individuals with ID [6].

Excessive accumulation of $\mathrm{Mn}$ in the brain by increased transferrin and transferring receptors leads to Mn toxicity, called manganism, which results in cognitive and mood abnormalities together with gait and speech abnormalities [7].

Iron supplementation not only corrects ID in ID subjects but also decreases blood Mn concentration [8]. Our aim was to study the changes in serum Mn before and after iron supplementation in children with ID.

\section{MATERIAL AND METHODS}

This interventional prospective study included 63 children aged 5-12 years, proven by laboratory investigations to have ID according to the guidelines of the WHO [1] (serum ferritin $\leq 30 \mathrm{mg} / \mathrm{l}$, transferrin saturation $\leq 16 \%$, mean cell volume $[\mathrm{MCV}] \leq 73 \mathrm{fl}$, and mean cell haemoglobin concentration $[\mathrm{MCHC}] \leq 32 \mathrm{~g} / \mathrm{l})$. The children were recruited from paediatric clinics, Medical Research Excellence Centre (MREC) between August 2017 and December 2018.

Exclusion criteria that might affect iron status included the following: chronic infections, chronic inflammatory diseases (rheumatic disease and inflammatory bowel disease), parasitic infestation, thalassemia traits A and B, lead toxicity, iron supplementation, and blood transfusion during the last six months. Exclusion criteria that might affect blood Mn level comprised cholestasis, total parenteral nutrition, malignancy, and renal disease. Thirty ageand sex-matched children were enrolled in the study as a control group. All the eligible children were subjected to full general and neurological history taking, especially dietetic history, iron supplementation during the last six months, easy fatigability, leg cramps on climbing stairs, school performance, and exam mark, to detect any abnormality in cognitive function, reduced resistance to infection, and any abnormalities in mood, speech, or gait.

Full clinical examination (general and neurological examination) of the studied children was carried out to detect signs of ID such as pallor of the mucous membranes, koilonychia, glossy tongue, atrophy of the lingual papillae, and angular stomatitis and manifestations of Mn toxicity as mood, speech, and gait abnormalities.

Sample collection of $5 \mathrm{ml}$ venous blood was withdrawn between 10 and 11 a.m. (to avoid diurnal variation); $1 \mathrm{ml}$ was collected into EDTA vacutainer tube for complete blood count (CBC) and $4 \mathrm{ml}$ was collected into plain tubes and centrifuged to obtain serum samples that were stored at $-80^{\circ} \mathrm{C}$ for further investigation. $\mathrm{CBC}$ was done by using a haematological autoanalyser. C-reactive protein (CRP) was measured using IMMUNOSPEC REFE29-056. Serum iron and total iron binding capacity (TIBC) were measured by automatic biochemistry analyser (Olympus Au 400). Transferrin saturation percentage was calculated as (serum iron / TIBC) $\times 100$. Serum ferritin was assessed by Biocheck, Inc. (cat. No. EC-1025). Serum transferring was measured using ELIZA (cat. No. E3273 Hu). Serum soluble transferrin receptor I (TfRI) was assessed using ELIZA (Cat. No. E0281Hu). Serum hepcidin was measured using ELIZA (Cat. No. E1019 $\mathrm{Hu}$ ). Serum Mn was assessed using inductively coupled plasma mass spectrometry (ICP-MS).

\section{ASSAY OF MANGANESE BY INDUCTIVELY COUPLED PLASMA MASS SPECTROMETER}

There are six fundamental compartments of a single quadrupole inductively coupled plasma mass spectrometer (ICP-MS): the sample introduction system, inductively coupled plasma (ICP), interface, ion optics, mass analyser, and detector.

All samples, standard and quality control materials were diluted 20 -fold using a solution containing approx. $0.7 \mathrm{mM}$ ammonia, $0.01 \mathrm{mM}$ EDTA, and $0.07 \%$ (v/v) Triton X-100, Butan-1-ol. Liquid samples were first nebulised in the sample introduction system, creating a fine aerosol that was subsequently transferred to the argon plasma. The high-temperature plasma atomises and ionises the sample, generating ions, which are then extracted through the interface region and into a set of electrostatic lenses called the ion optics. The ion optics focus and guide the ion beam into the quadrupole mass analyser. The mass analyser separates ions according to their masscharge ratio $(\mathrm{m} / \mathrm{z})$, and these ions are measured at the detector [9].

Oral iron therapy in the form of syrup (ferric ammonium citrate, elemental iron $10 \mathrm{mg} / 5 \mathrm{ml}$ in a dose of $10 \mathrm{mg} /$ day) according to Moretti et al., who found that these the standard dosing of iron supplements, was administered to the ID group for eight weeks [10]. The subjects were followed up every four weeks for eight weeks. Compliance and adverse effects were checked in each follow-up visit. Full history taking, complete physical examination, and laboratory investigations were repeated one day after completion of iron therapy.

Before the study, the guardians of the patients were informed about the content and type of the study, in- 
formed consent was obtained from the parents. This study was approved by Medical Research Ethical Committee (MREC) of the National Research Centre, registration number 18097.

\section{STATISTICAL ANALYSIS}

Statistical package for the social sciences (SPSS, version 15.0 for Windows; SPSS Inc., Chicago Illinois, USA) was used for statistical analysis. Continuous variables were expressed as mean \pm standard error. Comparisons between quantitative variables were done using the independent $t$-test. Paired sample $t$-test was used to compare means of two variables (pre- and post-iron therapy) within a group. Pearson correlation was used to compute the pairwise associations for a set of variables. Multiple regression analysis was used with blood Mn as the dependent variable and factors of iron status as independent variables. The $p$-values $\leq 0.05$ were taken as significant.

\section{RESULTS}

This study included 63 iron-deficient children ( 32 males and 31 females) their age ranged from 5 to 12 years with mean $9.63 \pm 0.78$ years, and their BMI ranged from 15.45 to 27.9 with mean $17.92 \pm 0.80 \mathrm{~kg} / \mathrm{m}^{2}$. They were compared with 30 age- and sex-matched healthy children as controls (18 males and 12 females) whose ages ranged from 5.5 to 14 years with mean $10.93 \pm 0.72$ years, and their BMI ranged from 12.44 to 30.9 with mean 17.45 $\pm 1.04 \mathrm{~kg} / \mathrm{m}^{2}$.

None of our patients had abnormality in mood, speech, or gait.
Table 1 shows CBC, iron indices, and serum $\mathrm{Mn}$ in the ID and control groups expressed as mean and standard error. There were significant reductions in HB, HCT, $\mathrm{MCV}, \mathrm{MCH}, \mathrm{MCHC}$, transferrin saturation percentage, serum iron, and serum ferritin and a significant increase in serum $\mathrm{Mn}$ in children with ID compared to controls. The serum transferrin receptor and transferrin were higher in the ID group compared to controls, but not significantly.

The mean serum hepcidin concentration was lower in the ID group $(325.61 \pm 68.15)$ than in controls (507.50 \pm 92.42 ), but not significantly.

Multiple regression analysis showed negative correlation between serum $\mathrm{Mn}$ and serum iron, serum ferritin, and transferrin saturation percentage $(r=-0.33$ and $p=0.01, r=-0.32$ and $p=0.01, r=-0.3$ and $p=0.02$ ), respectively. The adjusted $r^{2}$ value showed that the model (HB, HCT, MCV, MCH, MCHC, RDW, transferrin saturation percentage, serum iron, serum TIBC, and serum ferritin) could explain $20 \%$ of serum $\mathrm{Mn}$ variability $(p=0.04)$.

Table 2 shows multiple regression analysis coefficient results of serum $\mathrm{Mn}$ as the dependent variable, and haematological and iron indices as independent variables. It reveals that each unit of decrease in MCV value increased the Mn level by 0.055 ( $p=0.04)$.

Table 3 shows significant improvement in haematological indices - HB, HCT, MCV, and RDW ( $p=0.00$, $p=0.013, p=0.028, p=0.00$, respectively), and improved iron indices - serum iron, transferrin saturation percentage, and ferritin ( $p=0.00, p=0.002, p=0.00$, respectively). There was also a significant decrease in serum Mn level $(p<0.001)$ after iron supplementation in the ID group.

TABLE 1. Complete blood count iron indices and serum manganese in the iron deficiency group and control group

\begin{tabular}{|l|c|c|c|}
\hline Parameter & Controls & Patients & $p$-value \\
\hline HB $(\mathrm{gm} / \mathrm{l})$ & $12.58 \pm 0.22$ & $11.02 \pm 0.29$ & 0.001 \\
\hline HCT $(\%)$ & $35.93 \pm 0.62$ & $32.94 \pm 0.63$ & 0.004 \\
\hline MCV $(\mathrm{fl})$ & $76.53 \pm 0.99$ & $70.86 \pm 1.12$ & 0.002 \\
\hline MCH $(\mathrm{pg})$ & $26.70 \pm 0.44$ & $24.27 \pm 0.55$ & 0.005 \\
\hline MCHC $(\mathrm{g} / \mathrm{dl})$ & $34.82 \pm 0.31$ & $32.62 \pm 0.82$ & 0.01 \\
\hline RDW $(\%)$ & $11.91 \pm 0.38$ & $15.50 \pm 1.99$ & 0.07 \\
\hline Serum iron $(\mu \mathrm{g} / \mathrm{dl})$ & $91.50 \pm 4.37$ & $44.64 \pm 2.81$ & 0.001 \\
\hline Serum TIBC $(\mu \mathrm{g} / \mathrm{dl})$ & $316.07 \pm 6.75$ & $309.65 \pm 11.61$ & 0.68 \\
\hline Transferrin saturation\% & $29.44 \pm 1.54$ & $14.71 \pm 0.99$ & 0.001 \\
\hline Serum ferritin $(\mathrm{ng} / \mathrm{dl})$ & $114.75 \pm 17.00$ & $26.62 \pm 4.14$ & 0.001 \\
\hline Serum sTfR $(\mathrm{mg} / \mathrm{l})$ & $0.47 \pm 0.14$ & $0.62 \pm 0.14$ & 0.48 \\
\hline Serum transferrin $(\mathrm{mg} / \mathrm{l})$ & $20.02 \pm 1.55$ & $24.16 \pm 1.54$ & 0.08 \\
\hline Serum hepcidin $(\mathrm{ng} / \mathrm{ml})$ & $507.50 \pm 92.42$ & $325.61 \pm 68.15$ & 0.15 \\
\hline Serum manganese $(\mathrm{ppm})$ & $0.0167 \pm 0.006$ & $0.128 \pm 0.026$ & 0.001 \\
\hline
\end{tabular}

$H B$ - haemoglobin, $H C T$ - haematocrit, $M C V$ - mean cell volume, $M C H$ - mean cell haemoglobin, MCHC - mean cell haemoglobin concentration, RDW - red blood cell distribution width, TIBC - total iron binding capacity, sTfR - soluble transferrin receptor; $p$-values $<0.05$ are significant, data are expressed as mean \pm standard error 
TABLE 2. Coefficient results of serum manganese as dependent variable with haematological and iron indices as independent variables

\begin{tabular}{|l|c|c|c|c|}
\hline \multirow{2}{*}{ Parameter } & \multicolumn{2}{|c|}{ Unstandardized coefficients } & Standardised coefficients & \multirow{2}{*}{$p$-value } \\
\cline { 2 - 4 } & $\beta$ & Std. error & $\beta$ & 0.887 \\
\hline 1/(constant) & -0.116 & 0.793 & -0.287 & 0.389 \\
\hline Human transferrin receptor & -0.043 & 0.048 & -3.311 & 0.114 \\
\hline HB & -0.292 & 0.167 & 2.904 & 0.065 \\
\hline HCT & 0.106 & 0.051 & -2.663 & 0.043 \\
\hline MCV & -0.055 & 0.023 & 2.545 & 0.094 \\
\hline MCH & 0.100 & 0.053 & 0.433 & 0.206 \\
\hline MCHC & 0.021 & 0.016 & -0.769 & 0.112 \\
\hline RDW & -0.011 & 0.006 & 3.711 & 0.093 \\
\hline Transferrin saturation (\%) & 0.074 & 0.039 & -3.245 & 0.087 \\
\hline Serum iron & -0.021 & 0.011 & 1.127 & 0.185 \\
\hline Serum TIBC & 0.003 & 0.002 & -0.271 & 0.414 \\
\hline Serum ferritin & -0.001 & 0.001 & & \multirow{2}{*}{} \\
\hline
\end{tabular}

$1 /($ constant) - dependent variable: manganese, $H B$ - haemoglobin, $H C T$ - haematocrit, $M C V$ - mean cell volume, $M C H$ - mean cell haemoglobin, $M C H C$ - mean cell haemoglobin concentration, $R D W$ - red blood cell distribution width, TIBC - total iron binding capacity

Hepcidin also increased after iron treatment of ID group but was not statistically significant.

\section{DISCUSSION}

Iron is a very important trace element in our metabolism and ID is the most common nutritional deficiency [1]. It occurs when iron requirement and losses exceed iron absorption and is usually multifactorial [11].

Trace element interactions can play an important role in iron status. Present results demonstrated a close interaction between iron and $\mathrm{Mn}$, particularly in case of
ID due to similarities in their absorption and transport mechanisms [12].

$\mathrm{MCV}, \mathrm{MCH}$ and MCHC are good indicators of ID [1]. All showed significant decrease than controls in our study that agreed with [13].

Serum ferritin reflects stored iron, which is an early marker of the ID state; in our study it decreased significantly more in patients than in controls $(p<0.001)$. However, ferritin levels must be measured with caution because it is an acute-phase reactant, which increases with inflammatory conditions. Hence, CRP measurements are very important to rule out inflammation [14]. In our

TABLE 3. Comparison between haematological, iron indices, and serum manganese level before and after iron supplementation

\begin{tabular}{|l|c|c|c|}
\hline Parameter & Before iron therapy & After iron therapy & $p$-value \\
\hline HB $(\mathrm{gm} / \mathrm{l})$ & $11.01 \pm 0.29$ & $12.78 \pm 0.27$ & 0.001 \\
\hline $\mathrm{HCT}(\%)$ & $32.94 \pm 0.63$ & $35.58 \pm 0.68$ & 0.01 \\
\hline MCV $(\mathrm{fl})$ & $70.86 \pm 1.12$ & $74.99 \pm 1.23$ & 0.02 \\
\hline MCH $(\mathrm{pg})$ & $24.27 \pm 0.55$ & $25.09 \pm 0.52$ & 0.35 \\
\hline MCHC $(\mathrm{g} / \mathrm{dl})$ & $32.62 \pm 0.82$ & $33.59 \pm 0.20$ & 0.41 \\
\hline RDW $(\%)$ & $15.5036 \pm 1.89$ & $11.53 \pm 0.42$ & 0.05 \\
\hline Serum iron $(\mu \mathrm{g} / \mathrm{dl})$ & $44.64 \pm 2.80$ & $73.45 \pm 7.28$ & 0.001 \\
\hline Serum TIBC $(\mu \mathrm{g} / \mathrm{dl})$ & $309.65 \pm 11.61$ & $276.09 \pm 20.11$ & 0.12 \\
\hline Transferrin saturation $(\%)$ & $14.71 \pm 0.99$ & $25.26 \pm 2.84$ & 0.002 \\
\hline Serum ferritin $(\mathrm{ng} / \mathrm{dl})$ & $26.62 \pm 4.14$ & $199.67 \pm 27.09$ & 0.01 \\
\hline Serum sTfR $(\mathrm{mg} / \mathrm{l})$ & $0.62 \pm 0.14$ & $0.76 \pm 0.27$ & 0.63 \\
\hline Serum human transferrin $(\mathrm{mg} / \mathrm{l})$ & $24.16 \pm 1.66$ & $53.38 \pm 14.90$ & 0.06 \\
\hline Serum hepcidin $(\mathrm{ng} / \mathrm{ml})$ & $325.61 \pm 68.15$ & $423.75 \pm 86.62$ & 0.41 \\
\hline Serum manganese $(\mathrm{ppm})$ & $0.128 \pm 0.026$ & $0.002 \pm 0.001$ & 0.001 \\
\hline
\end{tabular}

$H B$ - haemoglobin, $H C T$ - haematocrit, $M C V$ - mean cell volume, $M C H$ - mean cell haemoglobin, $M C H C$ - mean cell haemoglobin concentration, RDW - red blood cell distribution width, TIBC - total iron binding capacity, sTfR - soluble transferrin receptor; $p$-values $<0.05$ are significant, data are expressed as mean \pm standard error 
study CRP was $<5$, meaning absence of an inflammatory condition.

Measurement of sTfR represents the functional iron compartment which is a good indicator for early detection of ID and is not affected by inflammation; serum sTfR reflects the degree of bone marrow erythropoiesis [15]. Our study showed higher sTfR in patients than in controls ( 0.626 vs. 0.472 , respectively), but was not statistically significant.

The sTfR measurement was a good indicator of the ID degree, better than serum ferritin or transferrin [16]. Use of both sTfR measurement and WHO criteria provided accurate determination of iron status in this study.

We found that serum hepcidin concentration was lower in the ID group $(325.61 \pm 68.15)$ than in controls (507.50 \pm 92.42$)$, but not significantly, and it increased after iron treatment in the ID group (423.75 \pm 86.62$)$, but again was not statistically significant; this agreed with another study which emphasised that ID down regulates hepcidin production and vice versa [4].

$\mathrm{Mn}$ is an essential trace element for normal metabolism of proteins, lipids, and carbohydrates, via its role as a cofactor in many enzymes [17]. It is also required in growth, reproduction, immunity, energy homeostasis, and antioxidant defence [18].

Our study demonstrated that serum Mn concentrations were higher in children with ID than controls with normal iron state, which may be related to excess $\mathrm{Mn}$ absorption from the gastrointestinal tract during ID, which agrees with data published by Kim and Lee [19] and Rahman et al. [13]. Recently, it has been illustrated that Mn and iron compete for the same transporter called divalent metal transporter 1 (DMT1); thus, any decrease in iron causes an increase in Mn transport not only into blood but also through blood brain barrier [20].

Iron deficiency state is accompanied by excess duodenal DMT1expression [21]. In dietary ID, Mn uptake increased instead of iron, and this explains increased concentrations of serum $\mathrm{Mn}$ in children with ID. After iron supplementation in this study for two months we found improvement in iron indices and a decrease in serum Mn level, which agrees with data published by Kim et al. [8] and Park et al. [22], who found that iron supplementation for one to six months improved significantly iron state and Mn level. There was an improvement in school performance and exam marks after iron supplementation, which may be due to increased serum iron or decreased Mn level or both; further study is needed. Conversely, Bjørklund et al. [23] showed that iron supplementation did not affect serum Mn status.

In this study the coefficient of multiple regression analysis with serum Mn revealed that MCV is the most common factor affecting Mn negatively, i.e. when MCV decreases serum Mn increases. It is known that MCV is a good indicator of ID [13]. Whereas our study showed that MCV was the main determinant of serum Mn, Meltzer et al. found that serum ferritin was the main determinant of Mn level in his study [24].

In our study serum Mn correlated negatively with iron indices, which agreed with Brna et al. [25] and Smith et al. [6], who found that Mn toxicity occurred with ID.

Manganism is the deposition of Mn in the brain, where it precipitates primarily in the globus pallidus and in the nigra para reticularis, which produces neurotoxicity in the form of neurodevelopmental and intellectual impairment [26]. MRI can be done to observe Mn deposition in the brain [27]. However, some studies showed normal MRI in patients with increased Mn level [6]. Measurement of serum Mn level is better for detection of manganism than MRI.

Even though manganism has been seen only in adults, Mn toxicity effects on childhood behaviour and development are of concern because children absorb more Mn when compared with adults [28]. Hence, children are more vulnerable to Mn toxicity if they have ID.

Serum Mn levels more than $20 \mu \mathrm{g} / \mathrm{l}(0.02 \mathrm{ppm})$ are considered toxic, but the amount of $\mathrm{Mn}$ within the red blood cells (not able to pass the blood-brain barrier) and the amount bound to plasma transferrin is not known. It is recognised that brain transferrin receptors increase during iron deficient state but not as abundantly as those of red blood cells [6]; however, Garcia et al. showed that ID may enhance Mn deposition in the brains of neonatal rats even in the absence of excess $\mathrm{Mn}$ in diet or environment [29].

In our study after iron supplementation for eight weeks, there was a marked decrease in serum $\mathrm{Mn}(0.128$ vs. $0.002 \mathrm{ppm}, p<0.001)$, which agrees with the results of Yapici et al. [30].

\section{CONCLUSIONS}

Serum Mn level increased markedly with ID and decreased after iron supplementation for eight weeks. Frequent check-ups for all children for early discovery of ID and treatment with iron fortification and healthy food to prevent neurodevelopmental and intellectual impairment due to decreased iron level and high serum Mn.

\section{ACKNOWLEDGEMENTS}

The authors are grateful to the Centre of Excellence for Medical Research at National Research Centre, Egypt for providing the laboratory facilities without which this work could not have been accomplished.

\section{DISCLOSURE}

The authors declare no conflict of interest. 


\section{REFERENCES}

1. World Health Organization. A guide for program managers. Iron deficiency anemia assessment, prevention and control. Geneva (Switzer land) 2001.

2. Al Ghwass MME, Halawa EF, Sabry SM, et al. Iron deficiency anemia in an Egyptian pediatric population: cross sectional study. Ann Afr Med 2015; 14: 25-31.

3. Eden AN. Iron deficiency and impaired cognition in toddlers: an underestimated and undertreated problem. Pediatr Drugs 2005; 7: 347-352

4. Pigeon C, Ilyin G, Courselaud B, et al. A new mouse liver-specific gene encoding a protein homologous to human antimicrobial peptide hepcidin, is overexpressed during iron overload. J Biol Chem 2001; 276: 7811-7819.

5. Haynes EN, Sucharew H, Hilbert TJ, et al. Impact of air manganese on child neurodevelopment in East Liverpool. Neurotoxicology 2018; 64: 94-102.

6. Smith EA, Newland P, Bestwick KG, et al. Increased whole blood manganese concentrations observed in children with iron deficiency anemia. J Trace Elem Med Biol 2013; 27: 65-69.

7. Menezes-Filho JA, Novaes CO, Moreira JC, et al. Elevated manganese and cognitive performance in school-aged children and their mothers. Environ Res 2011; 111: 156-163.

8. Kim Y, Park JK, Choi Y, et al. Blood manganese concentration is elevated in Iron deficiency anemia patients, whereasglobuspallidus signal intensity is minimally affected. Neurotoxicology 2005; 26: 107-111.

9. Liba A. Manganese analysis in whole blood: Expanding the analytical capabilities of ICP-MS. Agilent 8800 ICP-QQQ Application. Handbook $2^{\text {nd }}$ ed. 2015: 81.

10. Moretti D, Goede JS, Zeder C, et al. Oral iron supplements increase hepcidin and decrease iron absorption from daily or twice-daily doses in iron-depleted young women. Blood 2015; 126: 1981-1989.

11. Gudzune KA, Huizinga MM, Chang HY, et al. Screening and diagnosis of micronutrient deficiencies before and after bariatric surgery. Obes Surg 2013; 23: 1581-1589.

12. Roth JA, Garrick MD. Iron interactions and other biological reactionsmediating the physiological and toxic actions of manganese, Biochem Pharmacol 2003; 66: 1-13.

13. Rahman MA, Rahman B, Ahmed N. High blood manganese in iron-deficient children in Karachi. Public Health Nutr 2013; 16: 1677-1683.

14. Wang W, Knovich MA, Coffman LG, et al. Serum ferritin: past, present and future. Biochim Biophys Acta 2010: 1800: 760-769.

15. Beguin Y. Soluble transferrin receptors for the evaluation of erythropoiesis and iron status. Clin Chim Acta 2003; 329: 9-22.

16. Ooi CL, Lepage N, Nieuwenhuys E, et al. Pediatric reference intervals for soluble transferrin receptor and transferrin receptor-ferritin index. World J Pediatr 2009; 5: 122-126.

17. Aschner JL, Aschner M. Nutritional aspects of manganese homeostasis. Mol Asp Med 2005; 26: 353-362.

18. Avila DS, Puntel RL, Aschner M. Manganese in health and disease. Met Ions Life Sci 2013; 13: 199-227.

19. Kim Y, Lee BK. Iron deficiency increases blood manganese level in the Korean general population according to KNHANES 2008. Neurotoxicology 2011; 32: 247-254.

20. Fitsanakis VA, Zhang N, Garcia S, et al. Manganese (Mn) and iron $(\mathrm{Fe})$ : interdependency of transport and regulation. Neurotoxicol Res 2010; 18: 124-131.

21. Byrnes V, Barrett S, Ryan E, et al. Increased duodenal DMT-1 expression and unchanged HFE mRNA. Blood Cells Mol Dis 2002; 29: 251-260.
22. Park S, Sim CS, Lee H, et al. Blood manganese concentration is elevated in infants with iron deficiency. Biol Trace Elem Res 2013; 155: 184-189.

23. Bjørklund G, Aaseth J, Skalny AV, et al. Interactions of iron with manganese, Zinc, Chromium, and selenium as related to prophylaxis and treatment of iron deficiency. J Trace Elem Med Biol 2017; 41: 41-53.

24. Meltzer HM, Brantsæter AL, Borch-Iohnsen B, et al. Low iron stores are related to higher blood concentrations of manganese, cobalt and cadmium innon-smoking Norwegian women in the HUNT 2 study. Environ Res 2010; 110: 497-504.

25. Brna P, Gordon K, Dooley JM, et al. Manganese toxicity in a child with iron deficiency and polycythemia. J Child Neurol 2011;26: 891-894.

26. Crossgrove J, Zheng W. Manganese toxicity upon overexposure. NMR Biomed 2004; 17: 544-553.

27. Fitsanakis VA, Zhang N, Avison MJ, et al. The use of magnetic resonance imaging (MRI) in the study of manganese neurotoxicity. Neurotoxicology 2006; 27: 798-780.

28. Winder BS. Manganese in the air: are children at greater risk than adults? J Toxicol Environ Health 2010; 73: 156-158.

29. Garcia SJ, Gellein K, Syversen T, et al. Iron deficient and manganese supplemented diets alters metals and transporters in the developing rat brain. Toxicol Sci 2007; 95: 205-214.

30. Yapici Z, Tuschl K, Eraksoy M. Hypermanganesemia with Dystonia 1: A Novel Mutation and Response to Iron Supplementation. Mov Disord Clin Pract 2019; 12: 94-96. 